\title{
Laboratory Study on Changes in Gas Desorption Properties of Anthracite after Cyclic Loading
}

\author{
Tie Li $\mathbb{D}^{1,2}$ Dong Wang, ${ }^{1,2,3,4}$ Mei-Hua Liu, ${ }^{3,4}$ Liang Chen $\mathbb{D}^{5},{ }^{5}$ and Hao Liu ${ }^{6}{ }^{6}$ \\ ${ }^{1}$ State Key Laboratory of High-Efficiency Mining and Safety of Metal Mines, Ministry of Education, \\ University of Science and Technology Beijing, Beijing 100083, China \\ ${ }^{2}$ School of Civil and Resource Engineering, University of Science and Technology Beijing, Beijing 100083, China \\ ${ }^{3}$ China Coal Research Institute, Beijing 100013, China \\ ${ }^{4}$ National Key Lab of Coal High Efficient Mining and Clean Utilization (China Coal Research Institute), Beijing 100013, China \\ ${ }^{5}$ School of Safety Engineering, North China Institute of Science and Technology, Beijing 101601, China \\ ${ }^{6}$ College of Aerospace Engineering, Chongqing University, Chongqing 400044, China
}

Correspondence should be addressed to Liang Chen; chenliangncist@21cn.com and Hao Liu; liuhaocqu@cqu.edu.cn

Received 3 July 2021; Revised 18 October 2021; Accepted 15 November 2021; Published 26 December 2021

Academic Editor: Dawei Yin

Copyright $\odot 2021$ Tie Li et al. This is an open access article distributed under the Creative Commons Attribution License, which permits unrestricted use, distribution, and reproduction in any medium, provided the original work is properly cited.

\begin{abstract}
Coal mass is subjected to cyclic loading during pulsating hydraulic fracturing (PHF), and changes in its gas desorption properties affect gas drainage. Therefore, it is of great importance to correctly understand the influences of cyclic loading on the gas desorption properties of coal mass. Firstly, loading tests with different frequencies and amplitudes were performed on anthracite from Qinshui Basin (Shanxi Province, China) using a fatigue testing machine. Secondly, gas desorption tests were performed to determine the associated curves for each test group at different equilibrium pressures, and the initial desorption capacity and diffusion coefficient of the gas were calculated. Finally, the influence of different loading conditions on the gas desorption laws were analyzed. The test results demonstrate that a greater loading frequency increases the ratio of the initial desorption capacity so that the desorption rate of coal samples is higher, and the gas desorption properties become increasingly better in the initial stage. However, variations in the amplitude have minimal impact on the ratio of the initial desorption capacity. When the amplitude is too large in the initial stage, the diffusion coefficient decreases and the gas desorption properties worsen. In addition, the above test results are used to discuss the selection of the amplitude and frequency in the PHF process from a macroperspective. The contained research results provide an important theoretical basis for the field application of PHF technologies in coal mines.
\end{abstract}

\section{Introduction}

Coal and gas outburst are one of the major disasters that significantly threatens safe production in coal mines, with China being one of the countries with the most serious coal and gas outburst disasters in the world [1-3]. To date, with increased mining depths and intensities in coal mines, hazard factors such as high in situ stresses, gas pressures, and gas contents readily induce rock and gas dynamic disasters, which further affects safe production in coal mines and threatens the lives of underground workers [4-7]. After many field practices, it has been proven that gas drainage is an effective means to prevent and control gas disasters in coal mines and to develop and utilize gas in coal seams [8-10].

The permeability of coal seams is a key parameter that influences gas drainage effects $[11,12]$. However, the permeability of coal seams in China is generally low, which mostly ranges from $10^{-4}$ to $10^{-3} \mathrm{mD}$ at 3 to 4 orders of magnitude lower than those in the United States and Australia [13-15]. Existing studies show that technologies such as hydraulic slotting, fracturing, and flushing can effectively increase the permeability of coal seams, which improves the gas drainage effects [16-22]. Nevertheless, in recent years, it has been found that the engineering application of traditional hydraulic technologies requires the 
consumption of significant water resources to achieve the desired effects $[19,23]$. Moreover, it is difficult to apply such technologies in areas with water shortages $[24,25]$. To solve this problem, Li et al. [26] proposed the pulsating hydraulic fracturing (PHF) approach based on traditional hydraulic fracturing technologies. This method continuously injects pulsating water with a certain frequency into coal seams and produces a cyclic loading, unloading, and loading effect by controlling the pulsating water pressure. With an increasing number of cycles, fatigue failure gradually occurs in coal mass and some new pores and fractures are formed. These coalesce with preexisting pores to form an interconnected fracture network, which provides channels for gas migration and greatly improves the permeability of coal seams [27]. Xu et al. [28] and Ni et al. [29] separately performed PHF tests in Daxing Coal Mine in Tiefa coalfield, Liaoning Province, and in Changping Coal Mine in Qinshui coalfield, Shanxi Province, China. The field test results showed that the technology can safely and reliably improve gas drainage effects.

During gas drainage from coal seams, gas is first desorbed from the coal matrix and diffused into fractures before flowing into drainage boreholes under seepage effects $[30,31]$. Gas desorption is another important factor that impacts drainage effects. If coal mass has a strong gas desorption capacity, coalbed methane (CBM) adsorbed at the inner surface of pores in the coal matrix changes from an adsorbed state to a free state as much as possible, and the ability of CBM diffusion from the matrix and micropores to the fractures is improved [32]. Su et al. [33] demonstrated that pore structures in the coal mass significantly influence gas desorption properties. In the PHF process, pore structures in the coal matrix are likely to change to some extent under cyclic loading. Xie et al. [34] also proved such a perspective as they compared and analyzed pore structures in coal mass before and after PHF using a scanning electron microscope and found the preexisting pores after PHF, which change from small to large. However, the effects of cyclic loading on gas desorption properties have been rarely investigated to date. Therefore, to further understand the dynamics of gas migration in PHF processes, it is of great scientific importance to study the change laws of the desorption properties in coal mass under cyclic loading.

Based on the above research status, loading tests with different frequencies and amplitudes were performed on anthracite from Qinshui Basin, Shanxi Province, China, by utilizing a fatigue testing machine. Furthermore, gas desorption curves for each test group at different equilibrium pressures were obtained through gas desorption tests, and the initial desorption capacity and diffusion coefficient of the gas were calculated. Finally, this study analyzed the effects of different loading conditions on gas desorption laws and provides a discussion of the selection of the amplitude and frequency in the PHF process from a macroperspective. Therefore, the research results offer an important theoretical basis for field applications of PHF technologies in coal mines.

\section{Materials and Methods}

2.1. Coal Sample Preparation. Anthracite from the Qinshui Basin, Shanxi Province, China, was used for the coal samples in the tests. The coal samples were collected from a freshly exposed working face underground before being sealed and packed immediately and sent to the laboratory as fast as possible to prevent oxidization. The basic properties of the coal samples are shown in Table 1.

This study performed cyclic loading and methane desorption tests after processing the crushed coal samples into briquettes because the anisotropy of the coal sample could affect the test results. The briquettes were processed according to the following two primary steps:

(1) Preparation of pulverized coal: The coal blocks were ground into small powder particles using a crusher and a grinder and were screened repeatedly with standard sieves of 0.2 and $0.25 \mathrm{~mm}$. Thus, pulverized coal particles with particle sizes of $0.2-0.25 \mathrm{~mm}$ were obtained.

(2) Compression molding: Pulverized coal of $200 \mathrm{~g}$ was placed into a mold with a diameter of $50 \mathrm{~mm}$ and pressed for $20 \mathrm{~min}$ to shape the sample with a material testing machine at $200 \mathrm{t}$ under a molding pressure of $100 \mathrm{MPa}$. The pressure was increased to a preset value within $10 \mathrm{~min}$ at a loading speed of $20 \mathrm{kN} / \mathrm{min}$. The deviation in pressures caused the final molding pressure to be $197 \mathrm{kN}$.

2.2. Cyclic Loading Tests. To study the influences of cyclic loading with different frequencies and amplitudes on the gas desorption properties in anthracite, this research designed seven groups of loading conditions, as shown in Table 2.

During cyclic loading, the specimens were molded under pressure for $20 \mathrm{~min}$ together with the mold and were placed on the fatigue testing machine (Figure 1). Sine waves were applied on the coal samples for $6 \mathrm{~h}$ in total following the loading conditions in Table 2. After loading, the mold and specimen were removed, and the mold was opened with a wrench to retrieve the final specimen.

This paper mainly analyzes the effect of loading frequency and loading amplitude on the coal desorption performance. The loading frequencies were set to 4,7 , and $10 \mathrm{~Hz}$, and the loading amplitudes were set to $10-20,12-18$, and $14-16 \mathrm{MPa}$. For each experimental condition, three desorption tests were performed at different equilibrium pressures $(0.5,1,0$, and $1.5 \mathrm{MPa})$.

2.3. Gas Desorption Tests. In accordance with the Determination Method of Methane Adsorption Capacity in Coal (MT/T752-2004), the steps for the desorption tests are shown as follows:

(1) Loading samples: The coal samples that were subjected to cyclic loading were crushed with a hammer to obtain particles sized at $1-3 \mathrm{~mm}$ after screening. 
TABLE 1: Basic properties of the coal samples.

\begin{tabular}{lcccc}
\hline \multirow{2}{*}{ Property } & \multirow{2}{*}{ Type } & \multicolumn{2}{c}{ Proximate analysis (wt.\%) } \\
& & $M_{\mathrm{ad}}$ & $A_{\mathrm{ad}}$ & $V_{\mathrm{daf}}$ \\
\hline Value & Anthracite coal & 1.89 & 8.59 & 9.41 \\
\hline
\end{tabular}

$M_{\text {ad }}$, moisture content; $A_{\text {ad }}$, ash yield; $V_{\text {daf }}$, volatile matter.

TABle 2: Loading conditions for cyclic loading tests.

\begin{tabular}{lcc}
\hline Test number & Test condition & \\
Lmplitude of loading pressure (MPa) & Loading time (h) \\
\hline 1 & 10 & $12-18$ \\
2 & 7 & \\
3 & 4 & $10-20$ \\
4 & 7 & $14-16$ \\
6 & - & 15 \\
7 & - & - \\
\hline
\end{tabular}

Notes: Group Nos. 1-5 are the test groups that change the frequency or amplitude alone; group No. 6 is the control group with a constant frequency and amplitude; group No. 7 represents the blank control group without cyclic fatigue loading.

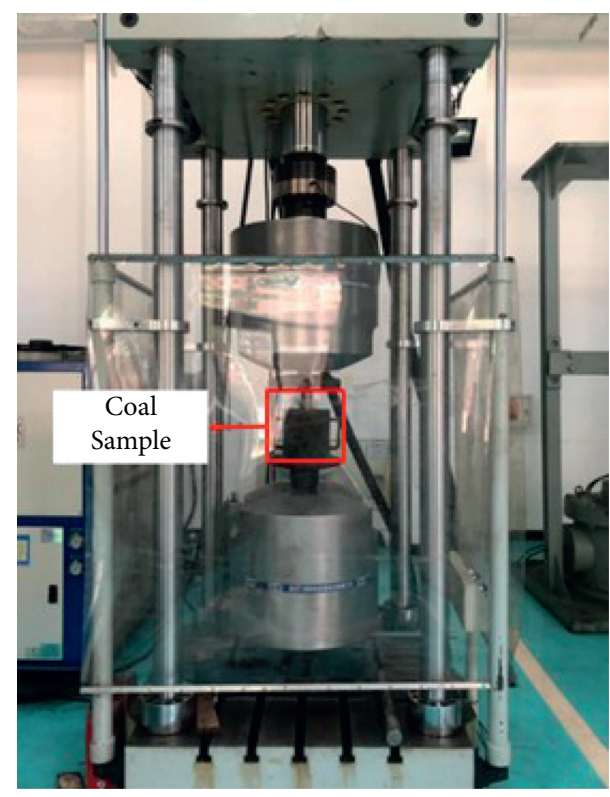

Figure 1: Fatigue testing machine.

Coal samples of $100 \mathrm{~g}$ in each test group were placed into numbered coal sample tanks.

(2) Gas filling and leakage detection: High-purity methane was filled to the three preset pressures of $0.5,1.0$, and $1.5 \mathrm{MPa}$ (pressure for adsorption equilibrium in the stable state) for each coal sample tank. The coal sample tanks were then placed into water to check for leakage. If there were no bubbles, the tank was qualified; otherwise, the tank was tightened or its sealing rings were replaced.

(3) Equilibrium adsorption: The qualified coal sample tanks after leak detection were placed in a constant temperature water bath at $30^{\circ} \mathrm{C}$ for adsorption equilibrium for more than $24 \mathrm{~h}$. The measured gas pressures, room temperatures, and atmospheric pressures of the correspondingly numbered coal sample tanks were recorded.

(4) Desorption tests: The coal sample tank valve was opened rapidly. When the pressure gauge dropped to zero, the tank was rapidly connected to an electronic flowmeter interfaced with a computer to constantly record the gas desorption capacities at different moments within $2 \mathrm{~h}$. After $2 \mathrm{~h}$ of desorption, the valve of the coal sample tank was quickly tightened.

(5) Laboratory test results under the pressure of adsorption equilibrium were obtained by repeating steps (1)-(4).

After completing the desorption tests, the final obtained desorption capacity was converted into a volume under standard conditions as

$$
Q_{t}=\frac{273.15}{101325\left(273.15+t_{w}\right)} *\left(P_{\mathrm{atm}}-9.81 h_{w}-P^{0}\right) * Q_{t}^{\prime},
$$

where $Q_{t}, Q_{t}^{\prime}$, and $t_{w}$ represent the volume $(\mathrm{mL})$ in the standard state converted from the total gas desorption capacity, total gas desorption capacity $(\mathrm{mL})$ measured during the tests, and room temperature $\left({ }^{\circ} \mathrm{C}\right)$ in the test, respectively; and $P_{\mathrm{atm}}, h_{w}$, and $P^{0}$ indicate the atmospheric pressure $(\mathrm{Pa})$ in the laboratory, height $(\mathrm{mm})$ of a liquid column in the apparatus for desorption when reading data, and the saturated steam pressure $(\mathrm{Pa})$ at the temperature $t_{w}$, respectively.

\section{Results and Discussion}

3.1. Analysis on Characteristics of Desorption Curves at Different Equilibrium Pressures. Figures 2 and 3 show the desorption curves of the briquette samples at the select equilibrium pressures $(0.5,1.0$, and $1.5 \mathrm{MPa})$ under different loading conditions. Because the production process of 


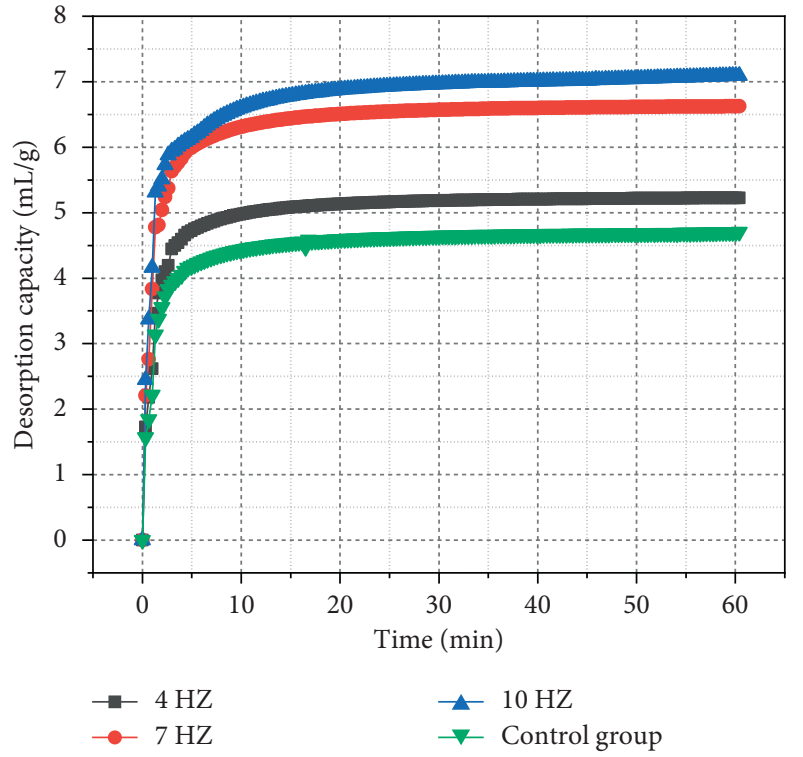

(a)

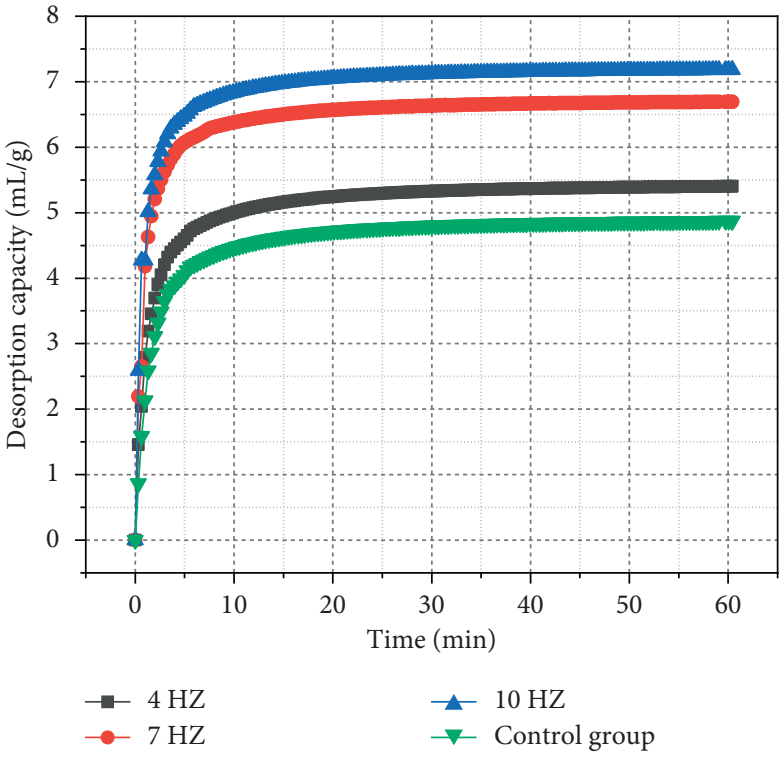

(b)

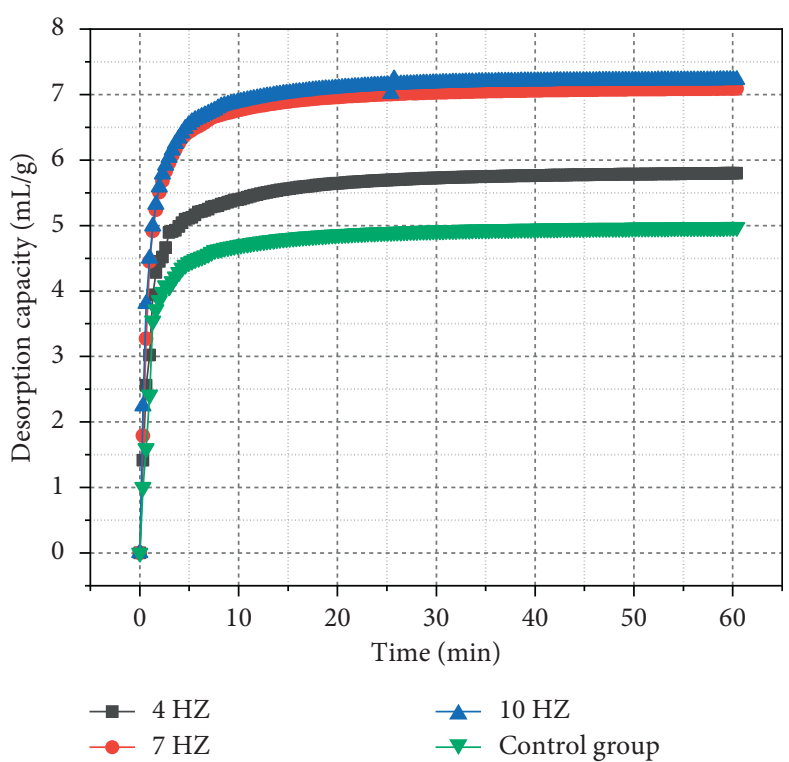

(c)

FIgURE 2: Desorption curves of the samples under different loading frequencies. (a) Equilibrium pressure of $0.5 \mathrm{MPa}$. (b) Equilibrium pressure of 1.0 MPa. (c) Equilibrium pressure of 1.5 MPa.

briquettes is different from that of common briquettes, the adsorption curves have certain differences from those of most coal mass analyses, but the general laws that govern this process are similar. The trends of the desorption curves for briquettes under different loading conditions are consistent. With an increasing desorption time, the desorption capacity from the briquette samples continuously increases and the initial desorption rate is rapid. After passing the early growth stage, the desorption rate drops sharply after $10 \mathrm{~min}$ and then becomes gentler. A faster initial gas desorption rate gives a quicker desorption rate attenuation. This is because when a coal sample tank is opened, the gas equilibrium state with a high concentration in the coal sample tank is broken instantly, and gas is desorbed from the adsorbed state. A higher equilibrium pressure gives a larger gas desorption capacity. However, due to the samples used in the tests, the curves are nearly flat in the later stage and the desorption capacities within $60 \mathrm{~min}$ are not significantly different at various equilibrium pressures.

Comparing the curves in Figures 2 and 3 indicates that the desorption capacities of the samples within $60 \mathrm{~min}$ are different for the various loading frequencies and amplitudes. As the frequency increases, the desorption capacity within 60 min rises slightly with an obvious difference. However, the amplitude has little influence and the desorption capacity shows a small difference under various amplitudes (except 


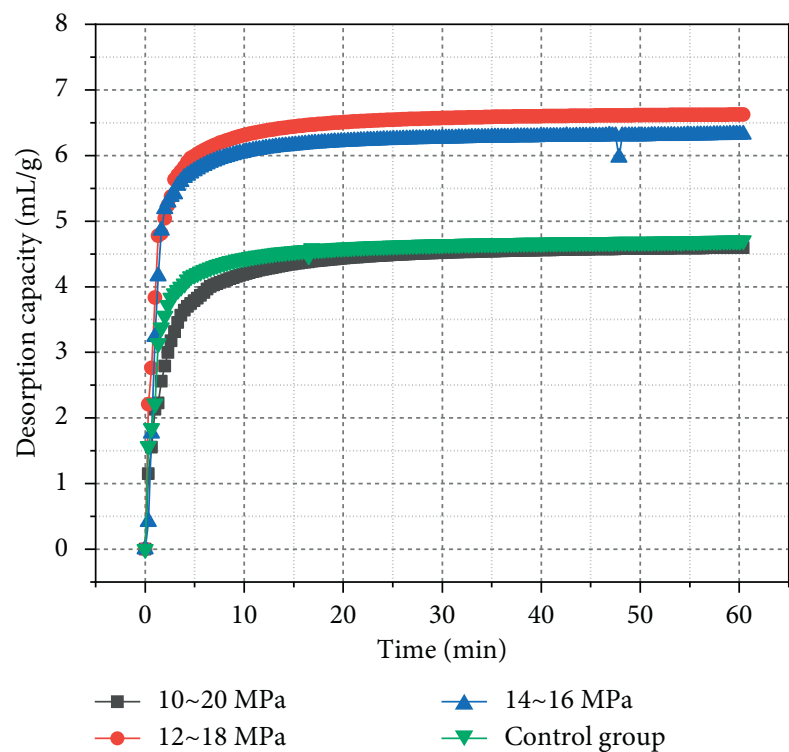

(a)

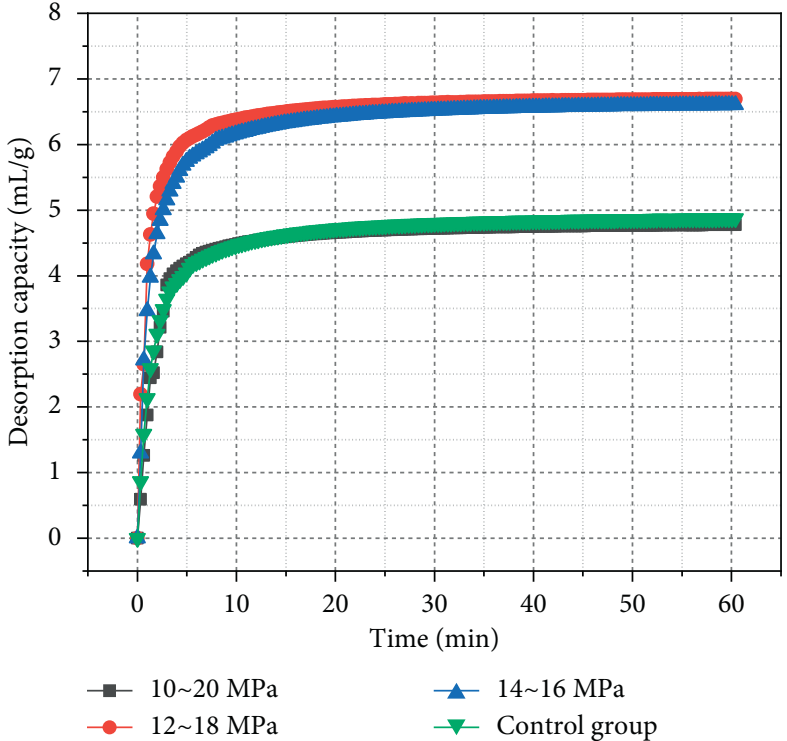

(b)

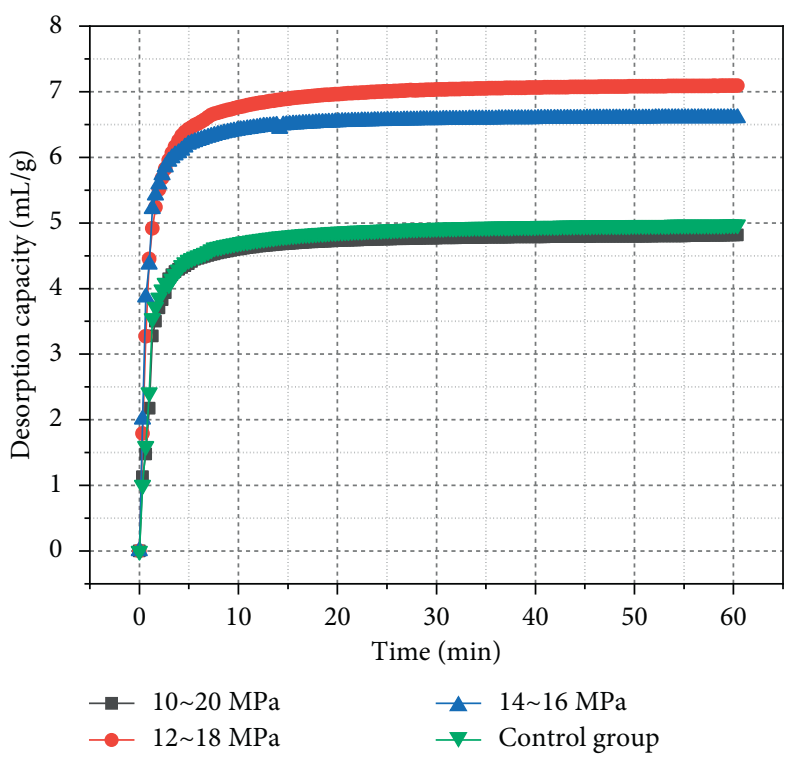

(c)

FiguRE 3: Desorption curves of the samples under different loading amplitudes. (a) Equilibrium pressure of $0.5 \mathrm{MPa}$. (b) Equilibrium pressure of 1.0 MPa. (c) Equilibrium pressure of 1.5 MPa.

for the test group under the amplitude of 10-20 MPa). After desorption on the pore surface, the adsorbed gas in the coal needs to enter the pore and fissure system of the coal body through diffusion, which then flows to the drainage hole via seepage. Therefore, the gas desorption characteristics significantly impact the gas drainage effect of the coal seam, which is discussed in Section 3.4.

3.2. Analysis on the Effects of Loading Frequency for Gas Desorption Parameters. The gas desorption curves in Section 3.1 indicate that the associated process in coal mass has a fast initial gas desorption that then attenuates quickly. Therefore, it is important to study the initial desorption capacity and diffusion coefficient. Combining pore volumes in each stage with the initial gas desorption capacity and diffusion coefficient allows studying the influences of a changing loading frequency on the gas desorption parameters. Taking the desorption capacity within $1 \mathrm{~min}$ in the early stage in the test as the initial desorption capacity allows investigating the relationship between the initial desorption rate and the characteristics of pores in the coal mass. The statistical results of the desorption capacities at different equilibrium pressures in each test group are given in Table 3.

Table 3 indicates that changes in the loading conditions influence the $Q_{1} / Q_{60}$ value. With a greater loading frequency, the ratio of the cumulative desorption capacity within $1 \mathrm{~min}$ to that within $60 \mathrm{~min}$ increases. The $Q_{1} / Q_{60}$ 
TABle 3: Cumulative desorption capacity from the briquettes under different loading frequencies.

\begin{tabular}{|c|c|c|c|c|c|}
\hline \multicolumn{2}{|c|}{ Loading conditions } & \multirow{2}{*}{$\begin{array}{l}\text { Equilibrium pressure } \\
\qquad(\mathrm{MPa})\end{array}$} & \multirow{2}{*}{$\begin{array}{l}\text { Desorption capacity within } 1 \mathrm{~min} \\
\left(Q_{1} / \mathrm{mL} \cdot \mathrm{g}^{-1}\right)\end{array}$} & \multirow{2}{*}{$\begin{array}{l}\text { Desorption capacity within } 60 \mathrm{~min} \\
\left(Q_{60} / \mathrm{mL} \cdot \mathrm{g}^{-1}\right)\end{array}$} & \multirow[b]{2}{*}{$\begin{array}{l}Q_{1} / Q_{60} \\
\quad(\%)\end{array}$} \\
\hline $\begin{array}{l}\text { Frequency } \\
(\mathrm{Hz})\end{array}$ & $\begin{array}{c}\text { Amplitude } \\
(\mathrm{MPa})\end{array}$ & & & & \\
\hline 4 & \multirow{3}{*}{$12-18$} & \multirow{4}{*}{0.5} & 2.62 & 5.23 & 50.07 \\
\hline 7 & & & 3.83 & 6.62 & 57.90 \\
\hline 10 & & & 4.16 & 7.09 & 58.70 \\
\hline- & 15 & & 2.22 & 4.70 & 47.18 \\
\hline 4 & \multirow{3}{*}{$12-18$} & \multirow{4}{*}{1.0} & 2.79 & 5.40 & 51.65 \\
\hline 7 & & & 4.18 & 6.69 & 62.48 \\
\hline 10 & & & 4.27 & 7.18 & 59.48 \\
\hline- & 15 & & 2.13 & 4.87 & 43.77 \\
\hline 4 & \multirow{3}{*}{$12-18$} & \multirow{4}{*}{1.5} & 3.02 & 5.80 & 52.10 \\
\hline 7 & & & 4.24 & 6.75 & 62.78 \\
\hline 10 & & & 4.50 & 7.22 & 62.27 \\
\hline - & 15 & & 2.41 & 4.97 & 48.56 \\
\hline
\end{tabular}

values in the test groups under the frequencies of 4 and $7 \mathrm{~Hz}$ are $50.07-52.1 \%$ and $57.90-65.78 \%$, respectively. The $Q_{1} / Q_{60}$ value for the test group under $10 \mathrm{~Hz}$ is slightly different from that for the test group under $7 \mathrm{~Hz}$, which ranges from 58.7 to $62.27 \%$. However, the $Q_{1} / Q_{60}$ value is in the range of $43.7-48.56 \%$ in the control group. Loading sine waves with different frequencies increases the gas desorption capacity by $16-34 \%$ in the early stage. The greater loading frequency (namely, the greater volume and specific surface area of pores) increases the ratio of the initial desorption capacity so that the desorption rate of the samples is larger. In addition, a greater equilibrium pressure causes a larger $Q_{1} / Q_{60}$ value. The increased ratio of the initial desorption capacity indicates that, in the initial stage, the desorption capacity is large and the desorption rate is greater.

The initial gas desorption capacity is calculated based on the relational expression between the initial gas diffusion coefficient and the square root of time proposed by Barrer [35] as

$$
Q_{i}=A \sqrt{t}
$$

where $Q_{i}, A$, and $t$ represent the initial gas desorption capacity, initial gas diffusion coefficient, and desorption time, respectively. In the test, gas desorption data within $2.64 \mathrm{~min}$ were used as the initial gas desorption capacity and the square root of time was regarded as the abscissa. Thus, the adsorption-desorption fit curves of the briquette samples at the selected equilibrium pressures $(0.5,1.0$, and $1.5 \mathrm{MPa})$ under different loading frequencies are drawn, as shown in Figure 4 . The fitting results are summarized in Table 4.

The fitting results indicate the curves have high fitting correlations with an $R^{2}$ coefficient that reaches 0.98 . The gas diffusion coefficient in the early stage is correlated with the pore characteristics in the coal samples, equilibrium pressure, and final gas desorption capacity. With a greater loading frequency, the gas diffusion coefficient gradually increases in the early stage. The diffusion coefficients in the test groups at frequencies of 4,7 , and $10 \mathrm{~Hz}$ are 2.6160-3.0828, 3.6011-3.7156, and 3.9855-4.0510, respectively, in the early stage, in which the maximum value is found in the test group under a frequency of $10 \mathrm{~Hz}$. In the control group under loading with a stable pressure, the diffusion coefficient ranges from 2.1588 to 2.6301. Applying sine waves with different frequencies increases the diffusion coefficient by $12-60 \%$ in the early stage, indicating that, with a larger loading frequency, the gas desorption properties become increasingly better in the early stage.

3.3. Analysis on Influences of Loading Amplitude on Gas Desorption Parameters. The data for the cumulative desorption capacities within 1 and $60 \mathrm{~min}$ when changing the loading amplitude are shown in Table 5.

Amplitude changes have minimal influence on the ratio of the initial desorption capacity. The $Q_{1} / Q_{60}$ value is maximized and reaches $57.90-62.78 \%$ in the test group under an amplitude of $12-18 \mathrm{MPa}$, while that in the test group under an amplitude of $14-16 \mathrm{MPa}$ is approximately $52 \%$ at the equilibrium pressures of 0.5 and $1.0 \mathrm{MPa}$. However, the $Q_{1} / Q_{60}$ value reaches $66.17 \%$ at the equilibrium pressure of $1.5 \mathrm{MPa}$. Compared with the control group (43.77-48.56\%), the $Q_{1} / Q_{60}$ value increases by approximately $32 \%$. The $Q_{1} / Q_{60}$ value is the minimum in the test group under an amplitude of 10-20 MPa, which is the only test group with a value smaller than the control group at around $93 \%$ of the control group. The adsorption-desorption fitting curves of the briquette samples at the selected equilibrium pressures $(0.5,1.0$, and $1.5 \mathrm{MPa})$ under different loading amplitudes are shown in Figure 5. A statistical analysis of fitting results is demonstrated in Table 6. The fitting results for each curve are highly linearly correlated and with an $R^{2}$ coefficient above 0.97 .

With a decreasing loading amplitude, the gas diffusion coefficient gradually increases in the early stage. The diffusion coefficients in the test groups under the amplitudes of $14-16,12-18$, and $10-20 \mathrm{MPa}$ are $3.2429-4.0132$, $3.6011-3.7156$, and $1.9808-2.5511 \mathrm{MPa}$, respectively. Compared with the effects of the loading frequency, changes in the loading amplitude lead to small changes in the diffusion coefficient. Compared with the diffusion coefficient in the control group, those in the test groups with amplitudes of $12-18$ and $14-16 \mathrm{MPa}$ increase by 


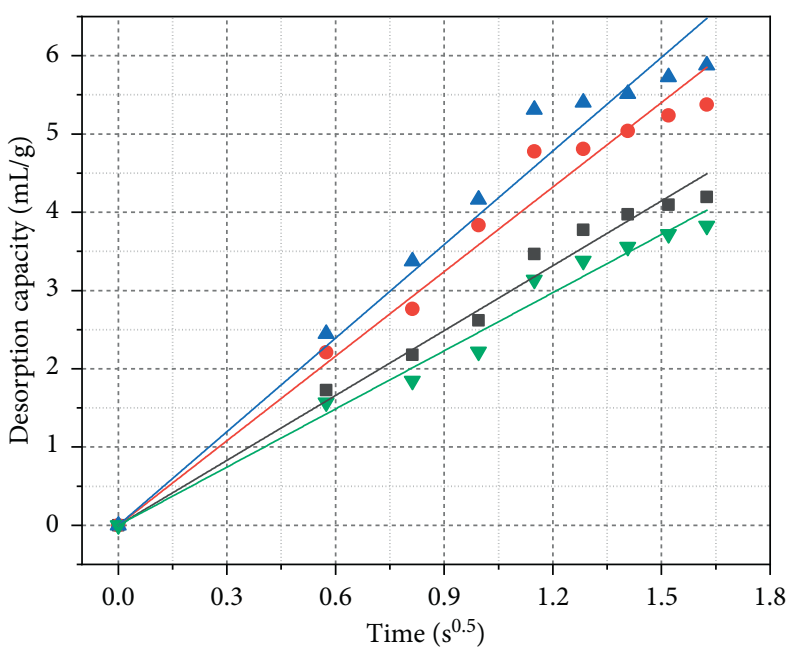

- $4 \mathrm{HZ}$

- $7 \mathrm{HZ}$
- $10 \mathrm{HZ}$

$\nabla$ Control group

(a)

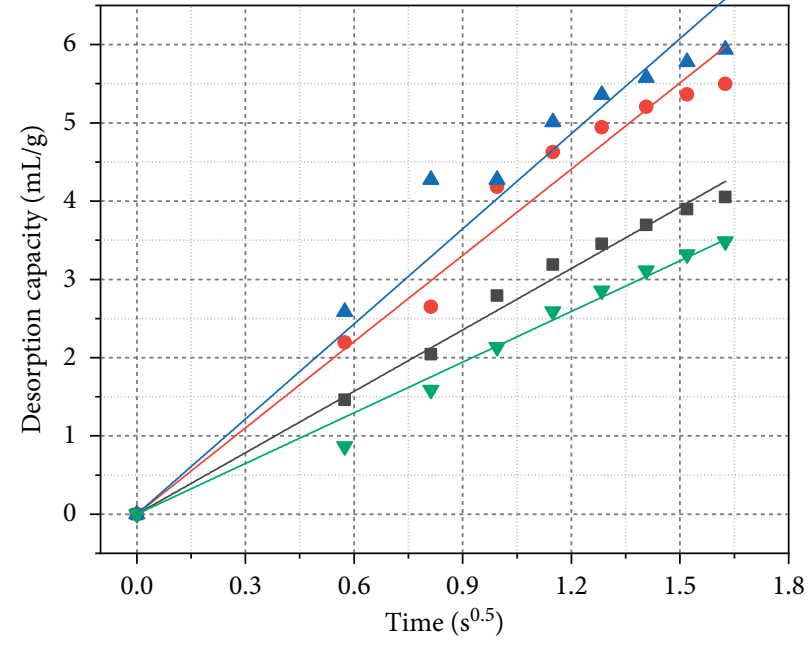

- $4 \mathrm{HZ}$

- $7 \mathrm{HZ}$

- $10 \mathrm{HZ}$

$\nabla$ Control group

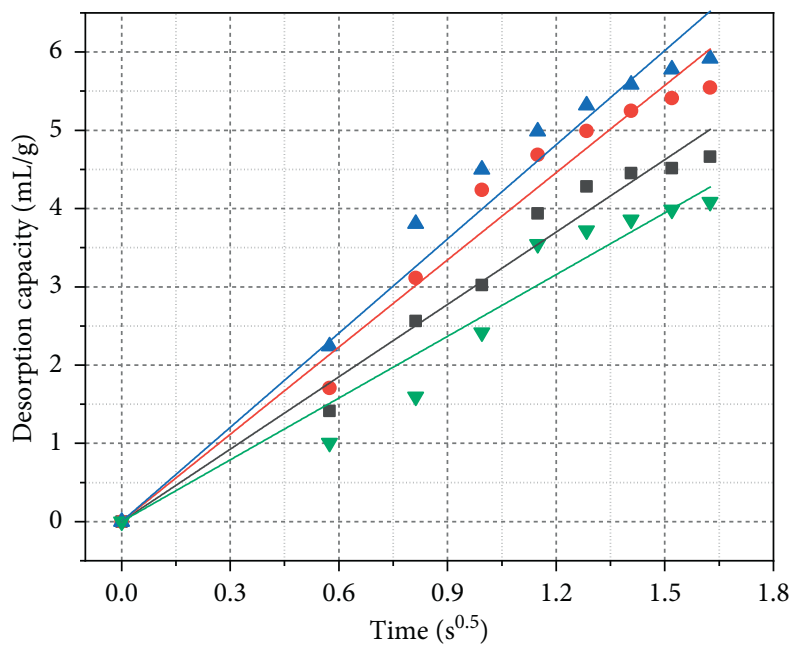

$\begin{array}{ll}\text { - } 4 \mathrm{HZ} & \Delta 10 \mathrm{HZ} \\ -7 \mathrm{HZ} & \boldsymbol{\nabla} \text { Control group }\end{array}$

(c)

FIGURE 4: Fit curves for the diffusion coefficient of the samples in the early stage under different loading frequencies. (a) Equilibrium pressure of $0.5 \mathrm{MPa}$. (b) Equilibrium pressure of 1.0 MPa. (c) Equilibrium pressure of $1.5 \mathrm{MPa}$.

TABLE 4: Fit results for the relationship between the desorption capacity of the briquette samples within 2.64 min and the square root of time under different loading frequencies.

\begin{tabular}{lcccccc}
\hline \multicolumn{2}{c}{ Loading conditions } & \multicolumn{2}{c}{$0.5 \mathrm{MPa}$} & \multicolumn{2}{c}{$1.0 \mathrm{MPa}$} & \multicolumn{2}{c}{$1.5 \mathrm{MPa}$} \\
Frequency $(\mathrm{Hz})$ & Amplitude $(\mathrm{MPa})$ & $A_{1}$ & $R^{2}$ & $A_{2}$ & $R^{2}$ & $A_{3}$ \\
\hline 4 & & 2.7635 & 0.9969 & 2.6160 & 0.9984 & 3.0828 \\
7 & $12-18$ & 3.6011 & 0.9946 & 3.6742 & 0.9945 & 3.7156 \\
10 & & 3.9855 & 0.9938 & 4.0510 & 0.9908 & 4.0128 \\
- & 15 & 2.4768 & 0.9962 & 2.1588 & 0.9965 & 2.6301 \\
\hline
\end{tabular}


TABLE 5: Cumulative desorption capacities of briquettes under different loading amplitudes.

\begin{tabular}{|c|c|c|c|c|c|}
\hline $\begin{array}{l}\text { Loading } \\
\text { conditions } \\
\text { Frequency }(\mathrm{Hz}) \\
\end{array}$ & $\begin{array}{l}\text { Amplitude } \\
(\mathrm{MPa})\end{array}$ & $\begin{array}{l}\text { Equilibrium pressure } \\
\qquad(\mathrm{MPa})\end{array}$ & $\begin{array}{l}\text { Desorption capacity within } \\
1 \mathrm{~min}\left(Q_{1} / \mathrm{mL}^{-1}\right)\end{array}$ & $\begin{array}{l}\text { Desorption capacity within } \\
\left.\quad 60 \mathrm{~min} Q_{60} / \mathrm{mL}^{-g^{-1}}\right)\end{array}$ & $\begin{array}{l}Q_{1} / Q_{60} \\
\quad(\%)\end{array}$ \\
\hline \multirow{3}{*}{7} & $10-20$ & \multirow{4}{*}{0.5} & 2.13 & 4.60 & 46.37 \\
\hline & $12-18$ & & 3.83 & 6.62 & 57.90 \\
\hline & $14-16$ & & 3.24 & 6.32 & 51.19 \\
\hline- & 15 & & 2.22 & 4.70 & 47.18 \\
\hline \multirow{3}{*}{7} & $10-20$ & \multirow{4}{*}{1.0} & 1.88 & 4.78 & 39.27 \\
\hline & $12-18$ & & 4.18 & 6.69 & 62.48 \\
\hline & $14-16$ & & 3.46 & 6.60 & 52.43 \\
\hline- & 15 & & 2.13 & 4.87 & 43.77 \\
\hline \multirow{3}{*}{7} & $10-20$ & \multirow{4}{*}{1.5} & 2.22 & 4.91 & 45.16 \\
\hline & $12-18$ & & 4.24 & 6.75 & 62.78 \\
\hline & $14-16$ & & 4.37 & 6.60 & 66.17 \\
\hline- & 15 & & 2.41 & 4.97 & 48.56 \\
\hline
\end{tabular}

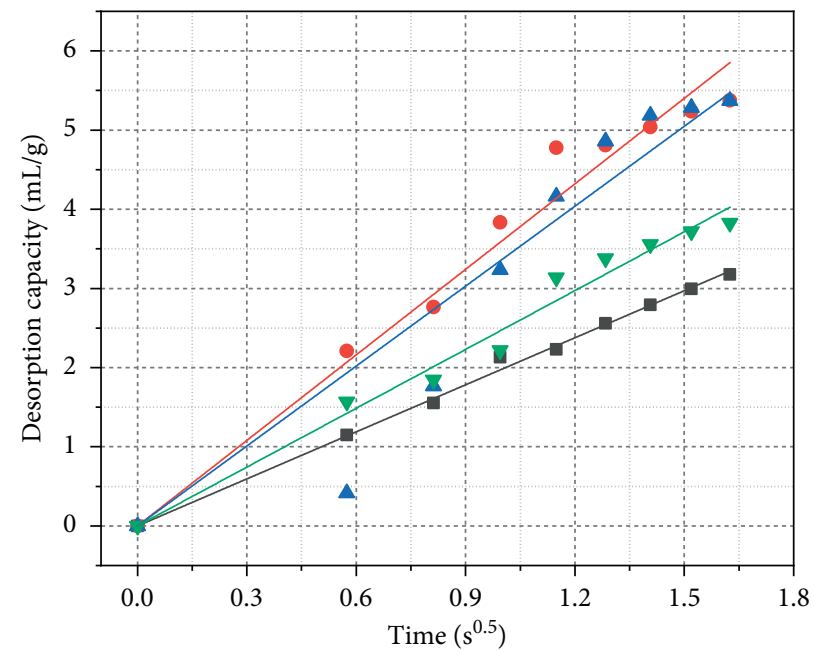

- $10 \sim 20 \mathrm{MPa}$

- $12 \sim 18 \mathrm{MPa}$
$\Delta 14 \sim 16 \mathrm{MPa}$

$\checkmark$ Control group

(a)

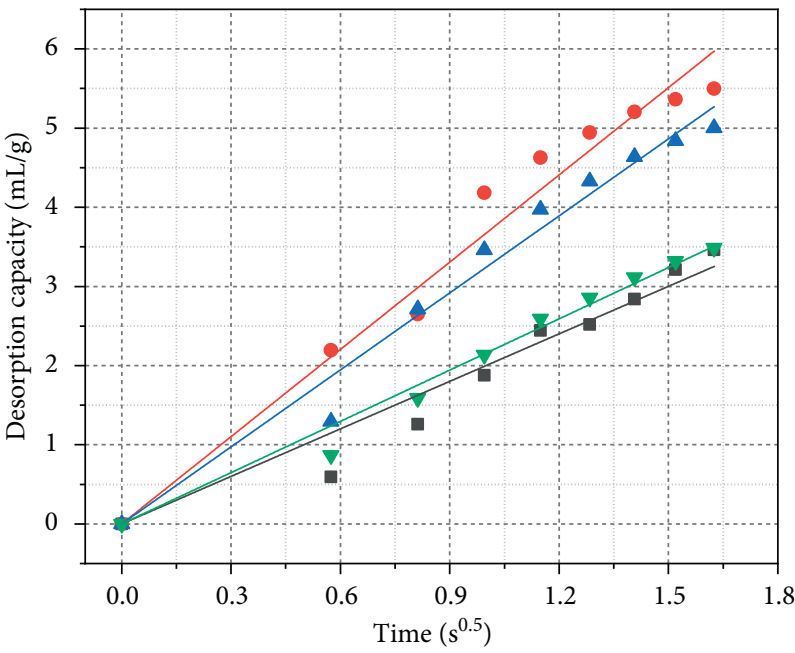

- $10 \sim 20 \mathrm{MPa}$

- $14 \sim 16 \mathrm{MPa}$

- $12 \sim 18 \mathrm{MPa}$

(b)

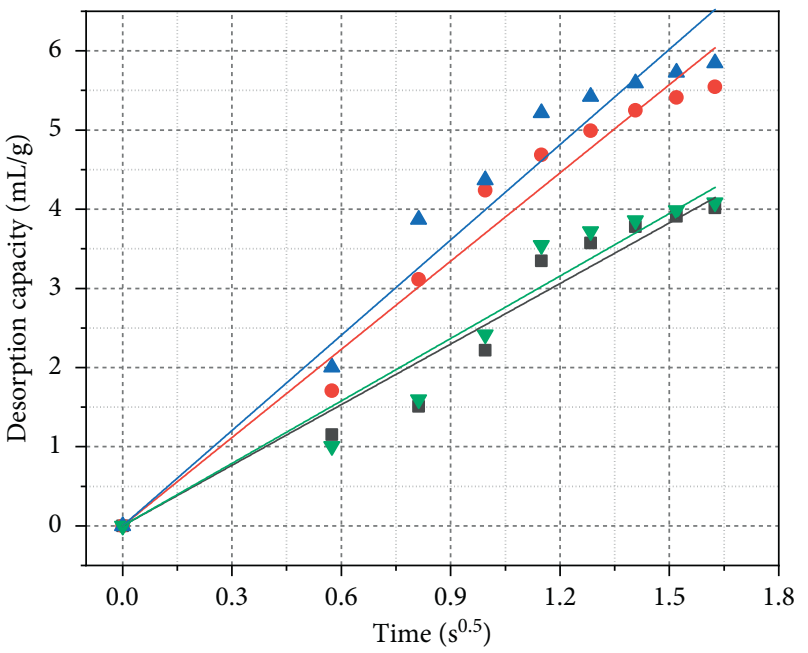

- $10 \sim 20 \mathrm{MPa}$

- $14 \sim 16 \mathrm{MPa}$

- $12 \sim 18 \mathrm{MPa}$

$\checkmark$ Control group

(c)

Figure 5: Fitting curves of the diffusion coefficients of the samples in the early stage under different loading amplitudes. (a) Equilibrium pressure of $0.5 \mathrm{MPa}$. (b) Equilibrium pressure of 1.0 MPa. (c) Equilibrium pressure of $1.5 \mathrm{MPa}$. 
TABLE 6: Fitting results for the relationship between the desorption capacity of the briquette samples within 2.5 min and the square root of time under different loading conditions.

\begin{tabular}{|c|c|c|c|c|c|c|c|}
\hline \multicolumn{2}{|c|}{ Loading conditions } & \multicolumn{2}{|c|}{$0.5 \mathrm{MPa}$} & \multicolumn{2}{|c|}{$1.0 \mathrm{MPa}$} & \multicolumn{2}{|c|}{$1.5 \mathrm{MPa}$} \\
\hline Frequency $(\mathrm{Hz})$ & Amplitude (MPa) & $A_{1}$ & $R^{2}$ & $A_{2}$ & $R^{2}$ & $A_{3}$ & $R^{2}$ \\
\hline \multirow[t]{3}{*}{7} & $10-20$ & 1.9808 & 0.9993 & 2.0010 & 0.9884 & 2.5511 & 0.9894 \\
\hline & $12-18$ & 3.6011 & 0.9946 & 3.6742 & 0.9945 & 3.7156 & 0.9939 \\
\hline & $14-16$ & 3.3655 & 0.9721 & 3.2429 & 0.9956 & 4.0132 & 0.9915 \\
\hline - & 15 & 2.4768 & 0.9962 & 2.1588 & 0.9965 & 2.6301 & 0.9875 \\
\hline
\end{tabular}

$36-45 \%$, while that in the test group under an amplitude of $10-20 \mathrm{MPa}$ is only approximately $0.8 \%$ of the control group. Applying sine waves with certain amplitudes can increase the gas diffusion coefficient in the early stage. However, when the amplitude is too large in the early stage, the diffusion coefficient is reduced and the gas desorption properties worsen.

3.4. Implications When Selecting Frequency and Amplitude during PHF. During PHF in underground coal mines, the ultimate goal is to improve the gas drainage [36, 37]. Research shows that, at larger frequencies, the gas desorption properties of the coal samples are increasingly enhanced. Therefore, after PHF, more adsorbed methane is converted into free molecules and diffuses into fractures. When there is more free methane in the fractures, the pressure gradient increases. According to Darcy's law, a larger pressure gradient inevitably increases the gas flow per unit time [38]. Therefore, more methane flows into the drainage boreholes. In addition, the results from Section 3.3 demonstrate that a greater loading amplitude can improve the gas desorption properties to a certain extent, but there is an optimum. In sum, in field construction, the PHF effects can be enhanced by increasing the frequency and adopting an optimal amplitude.

\section{Conclusions}

This study performed loading tests with different frequencies and amplitudes on anthracite from Qinshui Basin, Shanxi Province, using a fatigue testing machine. This research developed gas desorption curves in each test group at different equilibrium pressures through gas desorption tests and calculated the initial gas desorption capacity and diffusion coefficient. Finally, the influences of different loading conditions on the gas desorption laws were analyzed. The conclusions are drawn as follows:

(1) Applying sine waves of different frequencies increases the gas desorption capacity by $16-34 \%$ in the early stage. A greater loading frequency increases the ratio of the initial desorption capacity so that the desorption rate of the samples is larger. The diffusion coefficient increases by $12-60 \%$ in the early stage, indicating the gas desorption properties become increasingly better with the loading frequency.

(2) The influence laws of the changing amplitude on the ratio of the initial desorption capacity are minimal.
For the test groups under amplitudes of 12-18 and 14-16 MPa, a smaller frequency increases the $Q_{1} / Q_{60}$ value by about $32 \%$, while the $Q_{1} / Q_{60}$ value in the test group under an amplitude of $10-20 \mathrm{MPa}$ is only about $93 \%$ of the control group. Applying sine waves with certain amplitudes can increase the gas diffusion coefficient in the early stage. However, when the amplitude is too large, the diffusion coefficient reduces and the gas desorption properties worsen.

(3) In the PHF process for underground coal mines, the fracturing effects can be enhanced by increasing the frequency. However, economic costs need to be considered when selecting the proper frequency. In addition, when the amplitude is $12-18 \mathrm{MPa}$, the gas diffusion coefficient is the largest in the early stage. Therefore, the amplitudes in this range are selected for PHF. The research results provide an important theoretical basis for the field applications of $\mathrm{PHF}$ technologies in coal mines. This paper mainly analyzed the effects of the loading frequency and amplitude on the gas desorption characteristics. The relationship between the loading frequency and balance force is not considered and will be addressed in future studies.

\section{Data Availability}

All the data, models, and codes generated or used during this study appear in the manuscript.

\section{Conflicts of Interest}

The authors declare that there are no conflicts of interest regarding the publication of this article.

\section{Acknowledgments}

This work was supported by the National Natural Science Foundation of China (Grant nos. 52074120 and 51674016) and the Fundamental Research Funds for the Central Universities (3142019005).

\section{References}

[1] L. Qi, X. Tang, Z. Wang, and X. Peng, "Pore characterization of different types of coal from coal and gas outburst disaster sites using low temperature nitrogen adsorption approach," International Journal of Mining Science and Technology, vol. 27, no. 2, pp. 371-377, 2017. 
[2] J. Sobczyk, "A comparison of the influence of adsorbed gases on gas stresses leading to coal and gas outburst," Fuel, vol. 115, pp. 288-294, 2014.

[3] Q. Zou, H. Liu, Y. Zhang, Q. Li, J. Fu, and Q. Hu, "Rationality evaluation of production deployment of outburst-prone coal mines: a case study of Nantong coal mine in Chongqing, China," Safety Science, vol. 122, Article ID 104515, 2020.

[4] F. H. An and Y. P. Cheng, "An explanation of large-scale coal and gas outbursts in underground coal mines: the effect of low-permeability zones on abnormally abundant gas," Natural Hazards and Earth System Sciences, vol. 14, no. 8, pp. 2125-2132, 2014.

[5] E. Su, Y. Liang, Q. Zou, M. Xu, and A. P. Sasmito, "Numerical analysis of permeability rebound and recovery during coalbed methane extraction: implications for $\mathrm{CO}_{2}$ injection methods," Process Safety and Environmental Protection, vol. 149, pp. 93-104, 2021.

[6] H. Liu, H. Liu, and Y. Cheng, "The elimination of coal and gas outburst disasters by ultrathin protective seam drilling combined with stress-relief gas drainage in Xinggong coalfield," Journal of Natural Gas Science and Engineering, vol. 21, pp. 837-844, 2014.

[7] K. Jin, Y. Cheng, Q. Liu et al., "Experimental investigation of pore structure damage in pulverized coal: implications for methane adsorption and diffusion characteristics," Energy and Fuels, vol. 30, no. 12, Article ID 10383, 2016.

[8] J. Dong, Y. Cheng, K. Jin et al., "Effects of diffusion and suction negative pressure on coalbed methane extraction and a new measure to increase the methane utilization rate," Fuel, vol. 197, pp. 70-81, 2017.

[9] T. Liu, B. Lin, W. Yang, C. Zhai, and T. Liu, "Coal permeability evolution and gas migration under non-equilibrium state," Transport in Porous Media, vol. 118, no. 3, pp. 393-416, 2017.

[10] E. Su, Y. Liang, Q. Zou, F. Niu, and L. Li, “Analysis of effects of $\mathrm{CO}_{2}$ injection on coalbed permeability: implications for coal seam $\mathrm{CO}_{2}$ sequestration," Energy and Fuels, vol. 33, no. 7, pp. 6606-6615, 2019.

[11] Z. Pan and L. D. Connell, "Modelling permeability for coal reservoirs: a review of analytical models and testing data," International Journal of Coal Geology, vol. 92, pp. 1-44, 2012.

[12] T. Xia, F. Zhou, J. Liu, S. Hu, and Y. Liu, "A fully coupled coal deformation and compositional flow model for the control of the pre-mining coal seam gas extraction," International Journal of Rock Mechanics and Mining Sciences, vol. 72, pp. 138-148, 2014.

[13] T. Liu, B. Lin, and W. Yang, "Impact of matrix-fracture interactions on coal permeability: model development and analysis," Fuel, vol. 207, pp. 522-532, 2017.

[14] Q. Liu, Y. Cheng, H. Zhou, P. Guo, F. An, and H. Chen, "A mathematical model of coupled gas flow and coal deformation with gas diffusion and klinkenberg effects," Rock Mechanics and Rock Engineering, vol. 48, no. 3, pp. 1163-1180, 2015.

[15] E. Su, Y. Liang, X. Chang, Q. Zou, M. Xu, and A. P. Sasmito, "Effects of cyclic saturation of supercritical $\mathrm{CO}_{2}$ on the pore structures and mechanical properties of bituminous coal: an experimental study," Journal of $\mathrm{CO}_{2}$ Utilization, vol. 40, Article ID 101208, 2020.

[16] Q. Zou, Q. Li, T. Liu, X. Li, and Y. Liang, "Peak strength property of the pre-cracked similar material: implications for the application of hydraulic slotting in ECBM," Journal of Natural Gas Science and Engineering, vol. 37, pp. 106-115, 2017.
[17] Y. Zhao, B. Lin, T. Liu, Q. Li, and J. Kong, "Gas flow field evolution around hydraulic slotted borehole in anisotropic coal," Journal of Natural Gas Science and Engineering, vol. 58, pp. 189-200, 2018.

[18] A. Abdollahipour, M. F. Marji, A. Y. Bafghi, and J. Gholamnejad, "DEM simulation of confining pressure effects on crack opening displacement in hydraulic fracturing," International Journal of Mining Science and Technology, vol. 26, no. 4, pp. 557-561, 2016.

[19] Y. Lu, Z. Ge, F. Yang, B. Xia, and J. Tang, "Progress on the hydraulic measures for grid slotting and fracking to enhance coal seam permeability," International Journal of Mining Science and Technology, vol. 27, no. 5, pp. 867-871, 2017.

[20] Y. Liang, Y. Cheng, Q. Zou, W. Wang, Y. Ma, and Q. Li, "Response characteristics of coal subjected to hydraulic fracturing: an evaluation based on real-time monitoring of borehole strain and acoustic emission," Journal of Natural Gas Science and Engineering, vol. 38, pp. 402-411, 2017.

[21] J. Chen, X. Li, H. Cao, and L. Huang, "Experimental investigation of the influence of pulsating hydraulic fracturing on pre-existing fractures propagation in coal," Journal of Petroleum Science and Engineering, vol. 189, Article ID 107040, 2020.

[22] J. A. Wang and H. D. Park, "Fluid permeability of sedimentary rocks in a complete stress-strain process," Engineering Geology, vol. 63, no. 3, pp. 291-300, 2002.

[23] Y. Lu, X. Chen, J. Tang et al., "Relationship between pore structure and mechanical properties of shale on supercritical carbon dioxide saturation," Energy, vol. 172, pp. 270-285, 2019.

[24] Z. Jiang, Q. Li, Q. Hu et al., "Underground microseismic monitoring of a hydraulic fracturing operation for CBM reservoirs in a coal mine," Energy Science and Engineering, vol. 7, no. 3, pp. 986-999, 2019.

[25] Q. Zou, H. Liu, Z. Cheng, T. Zhang, and B. Lin, "Effect of slot inclination angle and borehole-slot ratio on mechanical property of pre-cracked coal: implications for ECBM recovery using hydraulic slotting," Natural Resources Research, vol. 29, 2019.

[26] Q. Li, B. Lin, and C. Zhai, "The effect of pulse frequency on the fracture extension during hydraulic fracturing," Journal of Natural Gas Science and Engineering, vol. 21, pp. 296-303, 2014.

[27] L. Chen, P. Li, G. Liu, W. Cheng, and Z. Liu, "Development of cement dust suppression technology during shotcrete in mine of China-A review," Journal of Loss Prevention in the Process Industries, vol. 55, pp. 232-242, 2018.

[28] J. Xu, C. Zhai, and L. Qin, "Mechanism and application of pulse hydraulic fracturing in improving drainage of coalbed methane," Journal of Natural Gas Science and Engineering, vol. 40, pp. 79-90, 2017.

[29] G. Ni, X. Hongchao, L. Zhao, Z. Lingxun, and N. Yunyun, "Improving the permeability of coal seam with pulsating hydraulic fracturing technique: a case study in Changping coal mine, China," Process Safety and Environmental Protection, vol. 117, pp. 565-572, 2018.

[30] H. Liu, B. Lin, and C. Jiang, "A new method for determining coal seam permeability redistribution induced by roadway excavation and its applications," Process Safety and Environmental Protection, vol. 131, pp. 1-8, 2019.

[31] H. Guo, Y. Cheng, L. Yuan, L. Wang, and H. Zhou, "Unsteady-state diffusion of gas in coals and its relationship with coal pore structure," Energy and Fuels, vol. 30, no. 9, pp. 7014-7024, 2016. 
[32] L. Si, Z. Li, Y. Yang, and R. Gao, "The stage evolution characteristics of gas transport during mine gas extraction: its application in borehole layout for improving gas production," Fuel, vol. 241, pp. 164-175, 2019.

[33] E. Su, Y. Liang, and Q. Zou, "Structures and fractal characteristics of pores in long-flame coal after cyclical supercritical $\mathrm{CO}_{2}$ treatment," Fuel, vol. 286, Article ID 119305, 2021.

[34] X. Jingna, X. Jun, N. Guanhua, S. Rahman, S. Qian, and W. Hui, "Effects of pulse wave on the variation of coal pore structure in pulsating hydraulic fracturing process of coal seam," Fuel, vol. 264, Article ID 116906, 2020.

[35] R. M. Barrer and D. E. W. Vaughan, "Sorption and diffusion of rare gases in heulandite and stilbite," Surface Science, vol. 14, no. 1, pp. 77-92, 1969.

[36] M. Mastalerz and A. Drobniak, "Coalbed methane," in Future Energy, T. M. Letcher, Ed., , Elsevier, Amsterdam, Netherlands, 3rd edition, 2020.

[37] J. Blunschi, T. Ertekin, and J. Wang, "Hydraulic fracturing mechanisms in coal: a review," International Journal of Oil, Gas and Coal Technology, vol. 14, no. 3, pp. 247-263, 2017.

[38] A. Mitra, S. Harpalani, and S. Liu, "Laboratory measurement and modeling of coal permeability with continued methane production: part 1-laboratory results," Fuel, vol. 94, pp. 110-116, 2012. 